\title{
Whistleblowing as Planned Behavior - a Survey of South Korean Police Officers
}

\author{
HEUNGSIK PARK, Professor \\ Chung-Ang University \\ Department of Public Administration, College of Political Science \& Economics \\ 221, Heukseok-Dong, Dongjak-Gu, Seoul 156-756 South Korea \\ E-mail: hspark@cau.ac.kr \\ JOHN BLENKINSOPP, PhD. \\ Reader in Management \\ Teesside Business School \\ Middlesbrough, UK \\ E-mail: john.blenkinsopp@tees.ac.uk
}

\begin{abstract}
This article explores the relevance of the Theory of Planned Behavior to whistleblowing research, and considers whether its widely tested validity as a model of the link between attitudes, intention and behavior might make it an appropriate candidate for a general theory to account for whistleblowing. This proposition is developed through an empirical test of the theory's predictive validity for whistleblowing intentions. Using a sample of 296 Korean police officers, the analysis showed attitude, subjective norm and perceived behavioral control all had significantly positive main effects on internal whistleblowing intentions, but for external whistleblowing intentions only subjective norm was significant. The implications of these findings for applying the Theory of Planned Behavior to whistleblowing research are discussed.

Keywords: whistleblowing, Theory of Planned Behavior
\end{abstract}

\section{INTRODUCTION}

The absence of a general theory of whistleblowing was first noted as a significant problem for researchers over twenty years ago (Miceli and Near, 1988) and despite a growing volume of high-quality research, the problem remains. It is a problem both theoretical and practical. Policymakers, both organizational and governmental, have a 
keen interest in the successful implementation of legal and organizational systems which would encourage the reporting of illegal or unethical behavior, yet without a comprehensive theoretical framework to account for whistleblowing behavior, researchers can offer only limited advice on the design of such systems.

In part the problem of theory development arises from the difficulties inherent in studying whistleblowing behavior directly, which led researchers to resort to indirect measures such as attitudes. Attitudes are however a problematic measure - though many employees have positive attitudes towards whistleblowing (they think it is morally right and necessary) few actually take action when the time comes to do so. This evidence of a disjunction between attitude and behavior led some researchers to use intention as a proxy measure for whistleblowing behavior, as intentions have proved to be better predictors of behavior than attitudes (Ajzen, 1988).

The present article seeks to draw together these two issues - the lack of a general theory, and the linkages between attitude, intention and behavior in whistleblowing through an examination of Ajzen's (1991) Theory of Planned Behavior (TPB). TPB is by far the most widely applied theory on the links between attitudes, intention and behavior, which makes it all the more surprising that whistleblowing researchers have thus far largely failed to draw upon it. TPB has already been shown to be an effective theoretical framework for predicting intentions of ethical behavior (Randall \& Gibson, 1991; Chang, 1998; McMillan \& Conner, 2003; Buchan, 2005) and the present article seeks to extend its application to the study of whistleblowing. In this article we will seek to demonstrate the utility of applying TPB to whistleblowing, through a study which tests two propositions derived from the theory.

The primary objectives of this study were to investigate the predictors of whistleblowing intentions and compare their roles in two types of whistleblowing internal and external. First, we examined the effects of attitude, subjective norms, and perceived behavioral control on whistleblowing intentions, all of which, the theory suggests, determine intentions and human behaviors. Second, we compared the influence of these three components on intentions in external versus internal whistleblowing. If we can successfully predict how an employee's intentions to blow the whistle are activated, it will be helpful to organizational leaders in their quest to instill an ethical culture and establish training programs that can more effectively influence employees to act ethically.

The article first reviews the Theory of Planned Behavior as a theoretical framework for predicting whistleblowing intentions, then develops research hypotheses that focus on the intentions of whistleblowing. Succeeding sections present the method of data 
collection and variable measurement, and examine the results of data analysis. Finally, we discuss the implications of our findings and the directions for future research.

\section{APPLYING THE THEORY OF PLANNED BEHAVIOR TO WHISTLEBLOWING}

Ajzen's (1991) theory of planned behavior (TPB) has already proved to be a useful theoretical tool to predict ethical or unethical behavior (Randall \& Gibson, 1991; Chang, 1998; McMillan \& Conner, 2003; Carpenter \& Reimers, 2005). For example, to predict the unauthorized copying of software, Chang (1998) evaluated the influence of the three components of the theory (attitude, subjective norm, and perceived behavioral control) on intention to behave unethically, using data from 181 university students. He found TPB was an effective theoretical framework in predicting intention for unethical behavior. Randall \& Gibson (1991) applied TPB to the prediction of ethical decisionmaking in the medical profession and reported that the theory successfully explained intent to report wrongdoing. In their study, attitudes, subjective norm, and perceived behavioral control accounted for a significant portion (61\%) of the variance in the intent of ethical decision making. Fukukawa (2002) applied TPB to a consumer's ethically questionable behavior in order to explain its complexity, and Bobek \& Hatfield (2003) employed the theory as a theoretical framework for exploring taxpayers' intentions to comply with tax laws. Parker et al. (1992) applied TPB to the prediction of drivers' intentions to commit driving violations, and their findings supported the theory for predicting these intentions. In addition, there have been a number of studies that used the theory to predict behavior pertaining to ethical issues, for instance, consumer misbehavior (Tonglet, 2002), dishonest actions (Beck \& Ajzen, 1991), and waste behavior (Teo \& Loosemore, 2001).

The Theory of Planned Behavior seems particularly suitable for explaining whistleblowing intentions, in that it is an action performed based on a highly complex psychological process (Gundlach et al, 2003). Furthermore Ajzen's theory has been widely accepted as a tool to analyze differences between attitude and intention as well as intention and behavior. In this respect, the attempt to use TPB as an approach to explaining whistleblowing may help overcome some of the limitations of previous studies, and provide a means to understand the widely observed gap between attitude and behavior.

TPB postulates that intention to carry out a behavior is a function of three types of underlying beliefs, which are conceptually independent of each other: (1) attitude 
toward the behavior, which is determined by beliefs about the consequences of that behavior, (2) a subjective norm about it, which is determined by normative beliefs, and (3) perceived behavioral control, which is determined by beliefs about resources and opportunities available to perform the behavior (Ajzen, 1991). An attitude is an individual's appraisal of how much he or she approves or disapproves of a specific behavior. In general, a person develops attitudes based on the beliefs he or she has about the behavior under consideration by associating that behavior with certain consequences. TPB assumes that beliefs about the consequences of a given behavior contribute to form the attitude toward that behavior. The degree of the belief in, and the subjective importance of, certain consequences interact to determine attitude toward the behavior. Thus, an attitude is sum of the products of the strength of each salient belief (in the consequences of a specific behavior) and the subjective evaluation of how much the belief's attributes are important (for that individual). An attitude toward whistleblowing (the extent to which an individual has a favorable or unfavorable evaluation of whistleblowing) is the sum of the products of the employee's beliefs about the consequences of whistleblowing and his or her subjective evaluation of those consequences. The consequences of whistleblowing, as they are implied in the objectives of whistleblower protection statutes (Callahan \& Dworkin, 2000), include prevention of harm to an organization, control of corruption, enhancement of public interest, an employee's doing his or her duty and moral satisfaction, etc. These are positive consequences, in that whistleblowing is largely considered as a positive behavior to be encouraged in a workplace.

A subjective norm is defined as "the perceived social pressure to perform or not to perform the behavior" (Ajzen 1991, p.188). It is based on normative beliefs, which are a person's thoughts about "the likelihood that important referent individuals or groups approve or disapprove of performing a given behavior" (Ajzen, 1991, p.195), and is represented by the sum of different normative beliefs multiplied by a person's motivation to meet the expectations of "important others", which for a whistleblower are family members, coworkers, immediate supervisor, friends, and neighbors.

The third determinant of intention, perceived behavioral control, refers to "the perceived ease or difficulty of performing the behavior" (Ajzen, 1991, p.188). According to the theory, a behavior or intention is dependent on the resources and opportunities available to an individual to perform a specific behavior (Ajzen, 1991). The obstacles or risks inherent in performing a behavior are termed control factors, and it is assumed that beliefs in them are influenced by past experience as well as secondhand information about the behavior acquired from the experiences of acquaintances 
and friends, or others (Ajzen, 1991). Thus, perceived behavioral control is a psychological construct rather than a measure of actual control although Ajzen (1991) notes that through experience the individual's perceived behavioral control will often approximate closely to actual behavioral control - in other words, we become astute judges of the constraints we face. Perceived behavioral control in whistleblowing can be estimated by means of both control factors and an evaluation of their importance. One of the control factors of whistleblowing comes from the beliefs about the organizational hindrances, namely, thwarting or intentional ignoring of the reporting. Another is associated with the personal negative beliefs, such as the perceived impossibility of successfully correcting the wrongdoing by reporting it in the organization, and concern about retaliation due to the reporting, with the latter being considered one of the most important control factors that discourage employees from reporting illegitimate activities (Miceli \& Near, 1992; Mesmer-Magnus \& Viswesvaran, 2005). To an employee who intends to blow the whistle it might be important how much he or she is protected from retaliation (Gorta and Forell, 1995) and certainly legislators have assumed that legal protection of whistleblowers is one of the most effective ways to encourage an employee to report wrongdoing in their organization.

TPB proposes that human behavior is influenced by these three factors through their influence on shaping an individual's intention to perform the behavior (Ajzen, 1987, 1991). Intention, which the theory defines as the extent to which an individual willingly tries to perform a specific behavior, is a central factor in motivating him or her to perform the behavior. Figure 1 shows how whistleblowing intentions would be predicted by the Theory of Planned Behavior.

Insert Figure 1 about here

A key issue which arises in examining whistleblowing intention is that whistleblowing is not a single behavior - there are various ways in which the individual employee might blow the whistle and there is no reason to assume that each way will be associated with the same attitudes, subjective norms and perceived behavioral control. Park et al. (2008) suggest six distinct ways to blow the whistle based on three choices which face the would-be whistleblower - internal versus external, anonymous versus identified, formal versus informal. Of these, the distinction between internal versus external whistleblowing is most widely discussed in the literature (Callahan \& Dworkin, 2000; Dworkin \& Callahan, 1991; Dworkin \& Baucus, 1998; Miceli \& Near, 1992) and 
would also seem to be likeliest to be associated with different attitudes, subjective norms etc. Dworkin \& Baucus (1998) reported that external whistleblowers tend to experience more extensive organizational retaliation than internal whistleblowers. External whistleblowing tends to cause greater damage to an employee's coworkers and the employer than internal whistleblowing, as the latter can give the organization an opportunity to fix inappropriate practices (Miceli \& Near, 1988). To justify external whistleblowing, the employee may be expected to exhaust the internal procedures available for report wrongdoing before s/he blows the whistle to the outside (Grant, 2002). The external whistleblower, who may be seen as a traitor by his or her employers and coworkers (Dworkin \& Callahan, 1991), is more likely to be subjected to retaliation than the internal whistleblower.

External and internal whistleblowing must therefore be treated as qualitatively different behaviors. For example, it would be quite possible for the same individual to view raising concerns about a matter within the organization as wholly appropriate, whilst considering the act of going to external agencies as a betrayal. Similarly, given the evidence that external whistleblowers experience much greater hostility and retaliation, we might expect there to be much more negative subjective norms and perceived behavioral control for this kind of whistleblowing. For all these reasons, we suggest that the effects of the three determinants in TPB (attitude, subjective norm, and perceived behavior control) will differ significantly in predicting intention for these two types of whistleblowing.

The underlying premise of this study is that the Theory of Planned Behavior may represent a parsimonious theoretical framework for predicting whistleblowing intentions. We have shown how this framework might be applied to whistleblowing, and why we might expect the three factors (attitude, subjective norm and perceived behavioral control) to show differing levels of influence for internal and external whistleblowing. We would expect attitude to be a significant predictor for both types of whistleblowing, but we suggest perceived behavioral control and subjective norm may have differing levels of influence for internal versus external whistleblowing. By choosing to blow the whistle externally, an individual avoids the many organizational barriers which exist for the internal whistleblower, and therefore perceived behavioral control is likely to be a less significant factor for external whistleblowing. However, external whistleblowers are aware their actions are likely to be viewed by their employers as a betrayal, and we might therefore expect that having the support of significant referents will be seen as important. For this reason, we suggest subjective norm will be a more significant factor for external whistleblowing. 
Hypothesis 1: Perceived behavioral control will be a better predictor of intentions for internal whistleblowing than external whistleblowing.

Hypothesis 2: Subjective norm will be a better predictor of intentions for external whistleblowing than internal whistleblowing.

Testing these hypotheses will contribute to expanding the knowledge needed for the improvement of a whistleblower protection system, the channels for reporting wrongdoing, and a training program for ethical management.

\section{METHODOLOGY}

\section{Data Collection}

The data for this study were collected from South Korean police officers between November 2003 and May 2004. The officers were all delegates on job-training programs at regional policy agencies and stations throughout the country. Questionnaires were distributed to 16 randomly selected sites, with 20-30 questionnaires allocated to each site, depending on class size. Five investigators, who had been instructed about the goals and contents of this study, visited these workplaces with the cooperation of the personnel department's chief officer. The questionnaire cover letter, which contained a short explanation of the study, assured respondents that their responses were for research purposes only and would be kept confidential. Questionnaires were collected directly from participants, and out of a sample of 400 officers at 16 sites, 296 police officers voluntarily completed the questionnaire, giving a $74 \%$ response rate. The respondents consisted of 217 males $(73.3 \%)$ and 79 females (26.7\%). Forty-four percent were between the ages of 30-39 years, while $39 \%$ were aged 40 or over. Over $75 \%$ had a college or graduate degree. Almost half (46.3\%) had been in the police force for 10 years or less, with 11.65 years being the average years of service.

\section{Questionnaire Design}

The questionnaire consisted of two parts. The first part measured whistleblowing intention and the three determinants of TPB, that is, attitude, subject norm, and perceived behavior control. Whistleblowing intention was measured through a total of 8 items, asking the question "If you found wrongdoing in your workplace, how hard would you try to do the following?" A 5-point Likert-type scale was employed to rate statements that ranged from Not at all (1) to Very hard (5). A principal axis factor 
analysis with varimax rotation of the 8 items resulted in two factors, 4 each for internal and external whistleblowing, and accounted for $72.3 \%$ of the variance with main factor loadings greater than .65 and no significant cross-loadings. The items, mean responses and Cronbach alpha values for the two scales are shown in Table 1a, and a factor analysis showing a clear two-factor solution is shown in Table $1 \mathrm{~b}$.

Insert Tables $1 \mathrm{a}$ and $1 \mathrm{~b}$ about here

Attitudes toward whistleblowing were measured by asking how true the respondent thought five statements were with regard to the salient consequences of an employee's reporting of wrongdoing in an organization. In addition, the respondents were asked to evaluate the importance of those consequences, under the question, "If you reported wrongdoing, how important do you think the following consequences would be to you?" Those five salient consequences of an employee's whistleblowing are: prevention of harm to the organization; control of corruption; enhancement of public interest; performing one's duty as an employee; and moral satisfaction on one's part. The statements or items under the above two questions were rated on a 5-point Likerttype scale. The scale of the first question was ranged from Not true (1) to Very true (5), and that of the second question, the importance of the five consequences was rated on the same scale from Not very important (1) to Very important (5). The responses to each statement given under the first question were multiplied by each evaluation of the five consequences respectively, and summed for the mean of the sample. Those statements, their means and the Cronbach alpha value are reported in Table 2.

Insert Table 2 about here

The overall means of the items of outcomes as well as their evaluation are higher than 3.50 on average, indicating that the respondents more or less agree whistleblowing has positive effects and they are important.

Subjective norm was measured by two questions. The first measured normative beliefs, which are a person's thoughts about the likelihood that important referent persons would approve or disapprove of a respondent's reporting of wrongdoing in an organization, asking, "How proud of you do you think the following persons would be if you reported wrongdoing?" The salient groups of referents were five: members of one's family, coworkers, immediate supervisor, friends, and neighbors. The respondent's motivations to comply with the expectations of the referents were 
measured by the second question, "How much do you care whether the following persons would approve or disapprove of your reporting of wrongdoing?" In both questions, the respondents were rated on a 5-point Likert-type scale ranging from Not much (1) to Very much (5) for the first question, and from Very little (1) to Very much (5) for the second question. The normal beliefs of approval or disapproval of the referents, which the respondents believe, was multiplied by the respondent's motivation to comply with the referents' demands, averaged and summed to produce subjective norm. Items and their means are reported in Table 3.

Insert Table 3 about here

The mean of the normal beliefs in the first question was highest (3.07, s.d.=1.27) for members of one's family, and lowest $(2.32$, s.d.=1.10) for immediate supervisor. The mean of the respondent's motivations in the second question was highest (3.31, s.d.=1.22) for members of one's family, compared with 2.90 (s.d.=1.20) for neighbors.

Perceived behavioral control was measured using eight items, four items for control factors and four items for the perceived power. The four control factor items are statements concerning beliefs or perceptions about difficulties to be faced in the process of the reporting as well as the results of an employee's reporting. The perceived power of the four control factors were measured as follows: an organization's hindering reporting (or ignoring it); difficulties to be faced in the process of reporting; no chance to correct wrongdoing; and retaliation by the organization. The respondents rated the items on a 5-point Likert-type scale. The control factor items were rated by a scale ranging from Not likely (1) to Very likely (5), and the perceived power items by a scale ranging from Not very important (1) to Very important (5). The perceived behavioral control was calculated by multiplying each control factor by the perceived power of each control factor, and summing the results across four control factors. For the items on control factors we invited respondents to gauge how difficult it would be to blow the whistle, and therefore a higher response indicated lower perceived behavioral control. We deliberately designed the survey in this fashion, as participants appear to find it easier to gauge difficulty rather than ease of reporting, but for data analysis we re-coded the responses such that a high score in the tables indicates high perceived behavioral control.

Insert Table 4 about here 
As shown in the Table 4, the range of values for perceived behavioral control was relatively narrow from 2.61 for "the difficulties to be faced in the process of my reporting", to 3.08 for "the organization will hinder/ignore my reporting every step of the way", and there are few differences in evaluated importance among the four items.

\section{ANALYSIS AND RESULTS}

Using the Theory of Planned Behavior as the basis for exploring how whistleblowing intentions are determined by belief systems, the authors conducted a correlation analysis of whistleblowing intentions and the three determinants of Ajzen's theory. Table 5 presents the descriptive statistics and the correlations among the variables.

Insert Table 5 about here

The results in Table 2 indicate that intention to blow the whistle internally ( $\mathrm{M}=$ $3.01)$ is higher than that for external whistleblowing $(\mathrm{M}=2.13)$ Both internal and external whistleblowing intentions were significantly related to the three determinants in TPB in the predicted direction, with the exception of the relations between external whistleblowing and perceived behavioral control which was in the predicted direction, but not significant. In their study of drivers' violations, Parker et al. (1992) found the relation between subjective norm and intention was stronger than that between attitudes and intention. Likewise, in this study the correlations of subjective norm with internal whistleblowing $(.419, \mathrm{p}<.000)$ and external whistleblowing $(.328, \mathrm{p}<.000)$ were stronger than those of attitude with internal and external whistleblowing $(.374$, $\mathrm{p}<.000$ and $.252, \mathrm{p}<.000$ respectively).

In order to examine in more detail the roles of the three determinants suggested by TPB, two regression analyses were conducted using whistleblowing intentions as the dependent variables. Table 6 shows the results of multiple regressions of whistleblowing intentions.

Insert Table 6 about here

As can be seen, for both types of whistleblowing the explanatory power of the three determinants is weaker than expected. For the regression analysis of internal whistleblowing intention, the independent variables explained 24.9 percent of the variance $(F=33.577, p=.000)$, with all three determinants being significant 
predictors. For external whistleblowing intention the independent variables explained 10.8 percent of the variance $(\mathrm{F}=12.828, \mathrm{p}=.000)$ but only subjective norm was a significant predictor in the regression model. Overall then, the results show that TPB has a significant capacity to predict whistleblowing intentions, but the effects of the determinants on an employee's intentions to blow the whistle differ depending on the type of whistleblowing.

Hypothesis I was that the effects of perceived behavior control will be greater on the intention of internal whistleblowing than that of external whistleblowing, and this is clearly supported. The effect of perceived behavioral control was significant for internal but not external whistleblowing intentions. Hypothesis II, that subjective norm will have a greater effect on intention for external whistleblowing than for internal whistleblowing, was neither clearly supported or rejected in the results of the regression analysis - the effect of subjective norm was positively significant for both internal and external whistleblowing, with similar B and beta values. However, what we can say is the subjective norm is clearly a more important predictor for external whistleblowing whereas for internal whistleblowing, all three TPB predictors are significant, for external whistleblowing intentions only attitude and subjective norm show a significant correlation, and only subjective norm is significant in the regression analysis.

\section{DISCUSSION}

The key findings of this study were twofold: (1) TPB is valid in predicting intentions to blow the whistle. Although its explanatory power wasn't as high as expected, it still adds to our understanding of what drives employees to blow the whistle, and shows that TPB has considerable potential as a parsimonious general theory for explaining whistleblowing; (2) The roles and effects of the three determinants of Ajzen's theory were different depending on the type of whistleblowing.

\section{Limitations of the study}

The choice of South Korean police officers as a sample is in itself a valuable contribution to whistleblowing research - in terms of both occupation and nationality they represent a very different population to those normally studied by whistleblowing researchers. We acknowledge that it is a very specific sample and as such lowers the external validity of the study, though the study might nevertheless be relevant to uniform services, or indeed any occupation where there is a strong emphasis on both hierarchy and a team ethos. However, before seeking to generalize from these results, 
one would need to repeat the study for a greater range of occupations.

Whilst our use of intention as a proxy measure of whistleblowing behavior represents a demonstrable improvement on the use of attitude as a proxy measure, it must always be acknowledged that failure to use whistleblowing behavior itself as the dependent variable is a limitation, notwithstanding the considerable challenges that would pose for the researcher.

\section{Implications for practice}

The findings have implications both for policymakers concerned with improving whistleblower protection and managers concerned with improving ethical behavior and risk management in their organizations. The formal channels for reporting inadequate or illegal practices in an organization, such as confidential telephone hotlines (now mandatory under the Sarbanes-Oxley Act), can be seen as a form of internal whistleblowing and our findings indicate that all three predictors represent important factors for increasing intention to blow the whistle internally. This suggests that interventions aimed at changing employees' attitude towards whistleblowing, the prevailing norms about it, and the extent to which they perceive they would be able to do so effectively, could all make a significant contribution to improving business ethics.

For organizations, the strategy of encouraging internal whistleblowing has two further benefits. Firstly, it improves risk management by making it less likely that unacceptable practices will go undetected. Secondly, by increasing the likelihood of internal whistleblowing, they should reduce the likelihood of external whistleblowing, which is generally viewed by organizations as having negative consequences for reputation. When an organization has put in place effective procedures for internal reporting, it might be legitimate for the organization to seek to discourage external whistleblowing, and our findings also suggest where management interventions might be targeted, for example on subjective norm and attitudes towards external whistleblowing (as perceived behavioral control does not appear to be a significant factor).

\section{Theoretical implications}

We noted at the outset that reliance on attitudes as a proxy measure has been a weakness in whistleblowing research, and in this study our use of TPB has allowed us to develop a usefully disaggregated analysis, separating attitude from intention and contributing to understanding of the gap between attitude toward whistleblowing and 
the actual intention to blow the whistle. The results suggest the difference between attitude and intention might be explained by the three determinants of TPB. The role of attitude toward whistleblowing was quite different in influencing intentions for internal versus external whistleblowing. For example, for external whistleblowing the only significant variable for predicting its intention was subjective norm. This suggests one way in which the gap of attitude and intention is created for the different behaviors of internal and external whistleblowing. The influence of attitude in explaining the intention of external whistleblowing is not as great as for internal whistleblowing, which explains why the widely-observed disjunction between attitude and intention is greater for external whistleblowing than internal. One way to interpret this is to think about the nature of the decision to blow the whistle (Blenkinsopp \& Edwards, 2008). Whereas internal whistleblowers may be surprised at the response to their reporting (Alford, 2001), the external whistleblowers know they are taking a major step which will not be well received by the organization. For them, the decision becomes less 'should I do this?' (attitude) or 'will I be able to do this?' (perceived behavioral control) but more 'will I survive doing this?' Such a decision will be crucially influenced by what they believe significant others will think of their actions. We might speculate whether there is also a methodological issue here, in that since external whistleblowing is clearly an altogether less likely act, participants are answering a much more hypothetical question - all four items for external whistleblowing intention show a lower response than even the lowest item for internal whistleblowing intentions.

\section{Implications for future research}

This study has a number of implications for future research. Firstly, and most obviously, there is a need to undertake similar research with a representative range of samples. There is no obvious reason to imagine that TPB would work as a general theory for South Korean police officers and no-one else, but the findings relating to which determinants best predict which type of whistleblowing need further research Ajzen (1991, p.188) notes that the relative importance of the determinants will vary according to behavior and situation. For example, Chang (1998) found in his study of the prediction of unauthorized copying of software, that perceived behavioral control was a better determinant in predicting behavioral intention than attitude, and subjective norm didn't have a significant direct effect on behavioral intention, but its indirect effect through attitude was highly significant. In future studies, it would be important to explore whether factors such as occupation or organization may influence the role 
played by the three determinants in explaining whistleblowing intentions.

Wated \& Sanchez (2005) suggest the roles of the three determinants could also significantly vary according to national cultural dimensions such as individualism or collectivism. For example, subjective norm might be more important in a collective society. Thus, a cross-cultural study of whistleblowing using the theory of planned behavior could contribute to the exploration of the roles that different underlying factors play in motivating individuals from different cultures to blow the whistle.

\section{CONLUSION}

The lack of a general theory has been a limitation to our understanding of whistleblowing. This study has attempted to explore the validity of Ajzen's Theory of Planned Behavior, which is widely accepted as a general framework for predicting behavioral intentions but is rarely used in whistleblowing studies. The results of this study showed TPB is valid as a general theory for explaining whistleblowing intentions, which adds to our understanding of the general approaches to whistleblowing described by earlier studies although we recognize that (in this study at least) the theory was more effective in explaining internal rather than external whistleblowing intentions. Among the three determinants of the theory taken into account, attitude and perceived behavioral control appear to be the most important factors to be considered if seeking to encourage internal whistleblowing. The findings could extend an organization's ability to predict whistleblowing intentions in the real world, and guide managerial efforts to improve the effectiveness of reporting channels aimed at ensuring the reporting of unethical practices within organizations.

\section{REFERENCES}

Ajzen, I. (1987). Attitudes, traits, and actions: Dispositional prediction of behavior in social psychology. Advances in Experimental Psychology, 20, 1-63.

Ajzen, I. (1991). The theory of planned behavior. Organizational Behavior and Human decision Processes, 50, 179-211.

Ajzen, I., Brown, T.C., \& Carvajal, F. (2004). Explaining the discrepancy between intentions and actions: The case of hypothetical bias in contingent valuation. Personality and Social Psychology Bulletin, 30(9), 1108-1121.

Beck, L., \& Ajzen, I. (1991). Predicting dishonest actions using the theory of planned behavior. Journal of Research in Personality, 25(3), 285-301.

Blenkinsopp, J., \& Edwards, M.S. (2008). On not blowing the whistle: Quiescent 
silence as an emotion episode. In W.J. Zerbe, C.E.J. Hartel and N.M. Ashkanasy (eds), Research on Emotions in Organizations Volume 4: Emotions, Ethics and Decision-Making. Bradford: Emerald.

Bobek, D.D., \& Hatfield, R.C. (2003). An investigation of the theory of planned behavior and the role of moral obligation in tax compliance. Behavioral Research in Accounting, 15, 13-38.

Buchan, H.F. (2005). Ethical decision making in the public accounting profession: An extension of Ajzen's theory of planned behavior. Journal of Business Ethics, 61, 165-181.

Callahan, E.S., \& Dworkin, T.M. (2000). The state of state whistleblower protection, American Business Law Journal, 38(1), 99-175.

Carpenter, T.D., \& Reimers, J.L. (2005). Unethical and fraudulent financial reporting: Applying the theory of planned behavior. Journal of Business Ethics, 60, 115129.

Chang, M.K. (1998). Predicting unethical behavior: A comparison of the theory of reasoned action and the theory of planned behavior. Journal of Business Ethics, 17(16), 1825-1834.

Dworkin, T.M., \& Callahan, E.S. (1991). Internal whistleblowing: Protecting the interests of the employee, the organization and society. American Business Law Journal, 29(2), 267-308.

Dworkin, T.M., \& Baucus, M.S. (1998). Internal vs. external whistleblowers: A comparison of whistleblowing processes. Journal of Business Ethics, 17(12), 1281-1298.

Fukukawa, K. (2002). Developing a framework for ethically questionable behavior in consumption. Journal of Business Ethics, 41(1/2), 99-119.

Gorta, A., \& Forell, S. (1995). Layers of decision: Linking social definitions of corruption and willingness to take action. Crime, Law \& Social Change, 23, 315-343.

Grant, C. (2002). Whistle blowers: Saints of secular culture. Journal of Business Ethics, 39(4), 391-399.

Gundlach, M. J., Douglas, S. C., \& Martinko, M. J. (2003). The decision to blow the whistle: A social information processing framework. Academy of Management Review, 28: 107-123.

Keenan, J.P. (1995). Whistleblowing and the first-level manager: Determinants of feeling obliged to blow the whistle. Journal of Social Behavior and Personality, 10(3), 571-584. 
McMillan, B., \& Conner, M. (2003). Applying an extended version of the theory of planned behavior to illicit drug use among students. Journal of Applied Social Psychology, 33(8), 1662-1683.

Mesmer-Magnus, J.R., \& Viswesvaran, C. (2005). Whistleblowing in organizations: An examination of correlates of whistleblowing intentions, actions, and retaliation. Journal of Business Ethics, 62, 277-297.

Miceli, M.P., \& Near, J.P. (1988). Individual and situational correlates of whistleblowing. Personnel Psychology, 41, 267-281.

Miceli, M.P., \& Near, J.P. (1992). Blowing the whistle - The organizational and legal implications for companies and employees. New York, NY: Lexington Books.

Park, H., Blenkinsopp, J., Oktem, M.K., \& Omurgonulsen, U. (2008). Cultural orientation and attitudes toward different forms of whistleblowing: A comparison of South Korea, Turkey, and the UK. Journal of Business Ethics, in press.

Parker, D., Manstead, A. S. R., Strading, S. G., Reason, J. T., \& Baxter, J. S. (1992) Intentions to commit driving violations: An application of the theory of planned behavior, Journal of Applied Psychology, 77, 94-101.

Randall, D.M., \& Gibson, A.M. (1991). Ethical decision making in the medical profession: An application of the theory of planned behavior. Journal of Business Ethics, 10(2), 111-122.

Teo, M.M.M., \& Loosemore, M. (2001). A theory of waste behavior in the construction industry. Construction Management and Economics, 19(7), 741-751.

Tonglet, M. (2002). Consumer misbehavior: An exploratory study of shoplifting. Journal of Consumer Behavior, 1(4), 336-354.

Wated, G., \& Sanchez, J.I. (2005). The effects of attitudes, subjective norms, attributions, and individualism-collectivism on managers' responses to bribery in organizations: Evidence from a developing nation. Journal of Business Ethics, 61, 111-127. 


\section{TABLE 1a}

Scale Items, Alpha and Means for Whistleblowing Intentions $(N=296)$

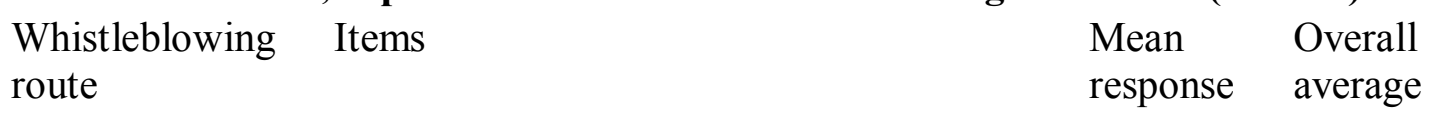

External $(\mathrm{EW})^{1} \quad$ Report it to the appropriate authorities 2.40 outside of the organization

Use the reporting channels outside of the 2.13 organization

Provide information to outside agencies $\quad 1.93$

Inform the public of it 2.05

Internal (IW) ${ }^{2} \quad$ Report it to the appropriate persons within 3.10 the organization

Use the reporting channels inside of the 3.11 organization

Let upper level of management know 2.90 about it Tell my supervisor about it

${ }^{1}$ Cronbach alpha $=.855,{ }^{2}$ Cronbach alpha $=.878$

\section{TABLE 1b}

\section{Results of Factor Analysis on Whistleblowing Intentions items $(N=296)$}

Items

Report it to the appropriate authorities outside of the organization

Use the reporting channels outside of the organization

Provide information to outside agencies

Inform the public of it

Report it to the appropriate persons within the organization

Use the reporting channels inside of the organization

Let upper level of management know about it

Tell my supervisor about it
F1 F2

$.786--.025$

$.777-.061$

$.748 \quad-.127$

$.677 \quad .051$

$-.018 \quad \mathbf{. 6 6 9}$

$-.014 \quad .663$

$-.172 \quad .660$

$.094 \quad \mathbf{6 5 9}$

Eigenvalues $\quad 13.84 \quad 11.55$

Cumulative Percents $\quad 19.49 \quad 35.75$

TABLE 2

Scale Items and Means for Attitude toward Whistleblowing (A) $(N=296)$

$\begin{array}{lccc}\text { Items } & \begin{array}{c}\text { Beliefs about the } \\ \text { consequences (b) } \\ \text { Mean (s.d.) }\end{array} & \begin{array}{c}\text { Evaluation of the } \\ \text { consequences (e) } \\ \text { Mean (s.d.) }\end{array} & \begin{array}{c}\text { (b x e) } \\ \text { Mean }\end{array} \\ \begin{array}{l}\text { Prevention of harm } \\ \text { to the organization }\end{array} & 3.80(1.12) & 3.84(1.09) & 15.20 \\ \begin{array}{l}\text { Control of } \\ \text { corruption }\end{array} & 3.86(1.02) & 3.72(1.06) & 14.92 \\ \begin{array}{l}\text { In the public interest } \\ \text { nat }\end{array} & 3.50(1.16) & 3.63(1.05) & 13.44\end{array}$


One's duty as a

$3.52(1.19)$

3.63(1.09)

13.51

public employee

$3.50(1.24)$

$3.71(1.12)$

Overall average

$3.64(.873)$

$3.71(.887)$

14.19

${ }^{1}$ Cronbach alpha $=.818$

A: Sum of $(b \times e)=70.94$ 
TABLE 3

Scale Items and Means for Subjective Norm (SN) $(N=296)$

$\begin{array}{lccc}\text { Items } & \begin{array}{c}\text { Normative beliefs (b) } \\ \text { Mean(s.d.) }\end{array} & \begin{array}{c}\text { Motivation to comply } \\ (\mathrm{m}) \\ \text { Mean(s.d.) }\end{array} & \begin{array}{c}\text { (b x m) } \\ \text { Mean }\end{array} \\ \begin{array}{l}\text { Members of one's } \\ \text { family }\end{array} & 3.07(1.27) & 3.31(1.22) & 10.73 \\ \begin{array}{l}\text { Coworkers } \\ \text { Immediate }\end{array} & 2.46(1.20) & 3.23(1.19) & 8.36 \\ \text { supervisor } & 2.32(1.10) & 3.15(1.20) & 7.68 \\ \text { Friends } & & & \\ \text { Neighbors } & 3.00(1.23) & 3.02(1.16) & 9.54 \\ \text { Overall average } & 2.84(1.28) & 2.90(1.20) & 8.77 \\ \text { SN: Sum } & 2.74(.922) & 3.12(.964) & 9.01\end{array}$

SN: Sum of $(\mathrm{b} \times \mathrm{m})=45.07$

TABLE 4

Scale Items and Means for Perceived Behavioral Control (PBC) $(N=296)$

Items

Belief in control

Evaluation of factors (bcf) ${ }^{1}$

control factors (ecf)

(bcf $x$ ecf)

Mean (s.d.)

Mean (s.d.)

Mean

The organization's

3.08(1.18)

3.26(1.17)

10.04

hindering reporting

(or ignoring it)

Difficulties to be

$3.29(1.14)$

8.59

faced in the process

of reporting

Reporting likely to

2.78(1.15)

$3.29(1.13)$

9.15

be ineffective in

ending wrongdoing

Retaliation by the

2.92(1.22)

$3.26(1.26)$

9.52

organization

Overall average

2.85(1.02)

3.30(.97)

9.41

${ }^{1}$ Cronbach alpha $=.868$

PBC: Sum of $($ bcf $x$ ecf $)=46.71$ 
TABLE 5

Descriptive Statistics and the Correlation between

Whistleblowing Intentions and the independent variables $(N=296)$

\begin{tabular}{|c|c|c|c|c|c|}
\hline & IW & $\overline{\mathbf{E W}}$ & $\overline{\mathbf{A}}$ & $\overline{\text { SN }}$ & $\overline{\mathrm{PBC}}$ \\
\hline IW & $\begin{array}{l}1.00 \\
\end{array}$ & & & & \\
\hline EW & $.446^{* *}$ & 1.00 & & & \\
\hline $\mathbf{A}$ & $.374 * *$ & $.252 * *$ & 1.00 & & \\
\hline SN & $.419 * *$ & $.328^{* *}$ & $.515^{* *}$ & 1.00 & \\
\hline PBC & $.278^{* *}$ & .028 & .094 & $.158^{* *}$ & 1.00 \\
\hline
\end{tabular}

1) $* * p<.01$; two tailed tests.

2) See Tables 1 to 4 for abbreviations. 
TABLE 6

Results of Multiple Regressions of the Three Determinants of Ajzen's Theory for Whistleblowing Intentions ( $=296)$

\begin{tabular}{lcccc}
\hline \hline Predictors & \multicolumn{2}{c}{$\begin{array}{c}\text { Dependent Variables } \\
\text { Internal } \\
\text { Whistleblowing }\end{array}$} & $\begin{array}{c}\text { External } \\
\text { Whistleblowing }\end{array}$ \\
\hline \hline Attitude toward Whistleblowing (A) & $.039^{* * *}$ & $(.215)$ & .017 & $(.110)$ \\
Subjective Norm (SN) & $.064^{* * *}$ & $(.277)$ & $.055^{* * *}$ & $(.275)$ \\
Perceived Behavioral Control (PBC) & $.074^{* * *}$ & $(.214)$ & -.008 & $(-.025)$ \\
Constant & \multicolumn{2}{c}{$1.236^{* * *}$} & \multicolumn{2}{c}{$1.448^{* * * *}$} \\
Adjusted R square & \multicolumn{2}{c}{.249} & \multicolumn{2}{c}{.108} \\
F value & \multicolumn{2}{c}{33.577} & \multicolumn{2}{c}{12.828} \\
Significance & \multicolumn{2}{c}{.000} & \multicolumn{2}{c}{.000} \\
\hline
\end{tabular}

1) $* * * \mathrm{p}<.001 ; 2$-tailed tests.

2) The figures in parentheses are standardized regression coefficients.

3) See Tables 1, 2, 3 and 4 for abbreviations.

FIGURE 1. Whistleblowing Intention in the Theory of Planned Behavior

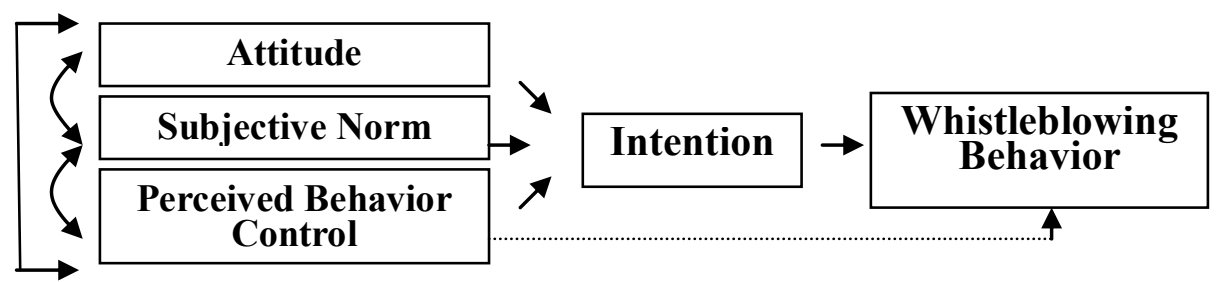

